\title{
Inventário Masculino dos Esquemas de Gênero do Autoconceito (IMEGA)
}

\author{
Adriana Giavoni ${ }^{1}$ \\ Universidade Católica de Brasília \\ Álvaro Tamayo \\ Universidade de Brasília
}

\begin{abstract}
RESUMO - O propósito deste artigo foi elaborar e validar o Inventário Masculino dos Esquemas de Gênero do Autoconceito (IMEGA). Baseado nas estruturas fatoriais das escalas masculina e feminina do Inventário dos Esquemas de Gênero do Autoconceito (IEGA), este instrumento avalia os esquemas masculino e feminino do autoconceito dos homens. A amostra utilizada foi composta por estudantes universitários do sexo masculino. Para a validade de construto do IMEGA, foram realizadas análises fatoriais (Principal Axis Factoring - PAF), com rotações oblíquas e ortogonais, para ambas as escalas e análise da consistência interna dos fatores (alfa de Cronbach). Os resultados demonstram que ambas as escalas são compostas por estruturas multifatoriais que se assemelham às estruturas fatoriais do IEGA. Devidamente validado, o IMEGA pode ser utilizado para avaliar os esquemas masculino e feminino do autoconceito de indivíduos do sexo masculino.
\end{abstract}

Palavras-chave: autoconceito; esquema masculino; esquema feminino.

\section{Masculine Inventory of the Self-Concept's Gender Squemas}

\begin{abstract}
The purpose of this article was the construction and validation of Masculine Inventory of the Self-Concept's Gender Schemas (IMEGA). Based on masculine and feminine scales that compose Gender Schemas of Self-Concept Inventory (IEGA), this instrument evaluates male self-concept's masculine and feminine schemas. The sample used was composed by male university students. For the construction validity, factors analysis were performed for both scales (Principal Axis Factoring - PAF) with oblique and orthogonal rotations) and the internal factors consistency analysis (coefficient alpha) were performed for all factors. The results showed that both IMEGA scales were composed by multifactorial structures that are alike IEGA's factorial structures. Properly validated, IMEGA could be used in the evaluation of male self-concept's masculine and feminine schemas.
\end{abstract}

Key words: self-concept; masculine schema; feminine schema.

William James (1890) pode ser considerado o precursor dos estudos empíricos na área de autoconceito. Segundo James, o self pode ser decomposto em dois importantes aspectos -I-selfe Me-self ${ }^{2}$. O I-selfé considerado como sujeito, o conhecedor; enquanto o Me-self é o objeto, o conhecido, um agregador de coisas e conceitos que, objetivamente, são considerados como pertinentes ao self. Enquanto conhecedor, o I-self é um centro ativo que avalia, associa e interpreta as experiências e que reconhece o $\mathrm{Me}$-self como sendo uma construção teórica realizada por ele mesmo. Harter (1996) descreve o Me-self como sendo um conceito análogo e precursor do autoconceito, tal qual o estudamos em psicologia.

Compartilhando deste pensamento, Epstein (1973) descreve o autoconceito como sendo uma autoteoria que o indivíduo, enquanto sujeito, elabora a respeito de si mesmo. Para o autor, esta "autoteoria" tem por finalidade: "a) optimizar o equilíbrio prazer/sofrimento durante o curso da vida; b) proteger e conservar a auto-estima e c) organizar as experiências, de tal forma que estas possam vir a ser enfrentadas com eficácia" (Epstein, 1973, p. 407).

1 Endereço: SHIS Q1 18 Conjunto 06 Casa 15, Brasília, DF, Brasil. 71650-065. E-mail: adriana@ pos.ucb.br

2 Neste trabalho, optou-se pelo emprego dos termos em inglês para designar os diferentes aspectos do self.
O autoconceito, portanto, é concebido como uma construção teórica que o indivíduo realiza sobre si, a partir de sua interação com o meio social. Esta autoconstrução é um reflexo das percepções, conjecturas e imaginações que o indivíduo realiza a respeito da influência que a sua imagem exerce sobre os outros, do julgamento que estes (outros significativos) realizam sobre o indivíduo, somados a uma espécie de auto-sentimento (orgulho ou vergonha) resultante desta interação social (Harter, 1996).

Através destas interações sociais, o indivíduo constrói, gradativamente, a sua identidade (Baldwin \& Holmes, 1987; Berndt \& Perry, 1986; Furman \& Buhrmester, 1985). Entretanto, esta identidade própria e singular que o diferencia dos demais, não se desvincula do social, mas continua a interagir com este e, inclusive, comporta-o em sua auto-estrutura (Banaji \& Prentice, 1994; Kashima \& cols., 1995; Markus \& Kitayama, 1991; Triandis, 1989).

Atualmente, o autoconceito vem sendo definido como uma estrutura multifacetada e maleável composta por uma coletânea de auto-representações. Um sistema que associa, organiza e coordena a variedade de imagens, esquemas, teorias, conceitos, metas e ideais que possuímos de nós mesmos (Bracken, 1996; Markus \& Kunda, 1986; Markus \& Nurius, 1986; Markus \& Wurf, 1987; Marsh, Barnes \& Richards, 1986; Sampson, 1985). 
Alguns autores salientam que esta estrutura multifacetada e maleável é formada por um cerne, ou núcleo, de conceitos importantes relacionados à identidade (Markus \& Kunda, 1986; Markus \& Nurius, 1986; Markus \& Wurf, 1987; Showers, Abramson \& Hogan, 1998). Estas auto-representações consideradas centrais foram denominadas de auto-esquemas (Markus, 1977; Markus \& Kunda, 1986; Markus \& Wurf, 1987). Os auto-esquemas "são construções que resumem nossas experiências passadas e que permitem aos indivíduos compreenderem suas próprias experiências sociais e a organizar a ampla variedade de informações que possuem sobre si mesmos" (Markus, Crane, Bernstein \& Siladi, 1982, p. 38). Além disso, os auto-esquemas moldam, filtram e guiam as percepções dos indivíduos, influenciando na forma como as informações são processadas. A vivência de experiências concernentes com a estrutura do esquema resulta em um esquema melhor articulado ou mais desenvolvido (Markus, 1977), propiciando padrões mais consistentes de comportamentos, julgamentos e decisões.

Dentre os auto-esquemas existem aqueles relacionados com o gênero. Quando estimulados, esses auto-esquemas tendem a se agrupar formando unidades de funcionamento específicas - os esquemas de gênero. Assim, na presença de estímulos específicos, indivíduos portadores de auto-esquemas relacionados à masculinidade, agrupam estes auto-esquemas formando uma rede de associações cognitivas - o esquema masculino. Processo semelhante ocorre para os indivíduos portadores de auto-esquemas relacionados à feminilidade, formando o esquema feminino.

Markus e cols. (1982) definem quatro grupos principais formados a partir dos esquemas de gênero: o esquemático masculino - formado por indivíduos portadores do esquema masculino, o esquemático feminino - formado por indivíduos portadores do esquema feminino, o andrógino - formado por indivíduos portadores dos dois esquemas de gênero e o indiferenciado - formado por indivíduos aesquemáticos em relação ao gênero. Para Markus e cols. (1982), o fato dos esquemáticos masculinos e dos esquemáticos femininos não apresentarem respostas relacionadas aos conceitos de feminilidade e masculinidade, respectivamente, não significa que estes não possuam conhecimentos relativos a estes conceitos. Mas, sim, que os conhecimentos que possuem não são relevantes em suas autodescrições, ou seja, não são auto-esquemas.

Entretanto, uma vez que a cultura possui papel preponderante sobre a formação do autoconceito e sendo a masculinidade e a feminilidade construções sócio-culturais, como é possível encontrar indivíduos aesquemáticos em relação ao gênero?

Se os esquemas cognitivos variam quanto ao nível de desenvolvimento - de simples a complexos, pode-se esperar que os esquemas de gênero também variem quanto à complexidade. Levando-se em consideração que a percepção da existência do esquema encontra-se diretamente correlacionada ao nível de desenvolvimento do mesmo (Burke, Kraut \& Dworkin, 1984; Rushton, Jackson \& Paunonen, 1981), pode-se, então, postular que os indivíduos possuem, em menor ou maior grau de complexidade, os esquemas masculino e feminino como dimensões constitutivas do autoconceito.

Neste sentido, os grupos supracitados de Markus e cols. (1982) seriam resultantes de diferentes combinações entre estes dois esquemas cognitivos. Por não considerarem o nível de desenvolvimento dos esquemas, estes autores desconsideraram a hipótese de que os indivíduos aesquemáticos viessem a ser indivíduos esquemáticos, mas com esquemas pouco desenvolvidos. De igual forma, pode-se considerar que os esquemáticos masculinos e os esquemáticos femininos possuam estruturas rudimentares dos esquemas feminino e masculino, respectivamente.

Desta forma, sendo o autoconceito uma estrutura que sofre a influência da cultura e sendo os conceitos de masculinidade e feminilidade construções da subjetividade social, pode-se postular que, dentre outros aspectos, o autoconceito seja formado por duas estruturas cognitivas que comportam os conceitos de masculinidade e feminilidade na subjetividade individual. Estas estruturas são os esquemas masculino e feminino. O estudo de Giavoni e Tamayo (2000) demonstra que o autoconceito é formado por estas duas estruturas cognitivas, as quais reúnem em si características individualistas e coletivistas, respectivamente, assim como os conceitos de masculinidade e feminilidade (Flaherty \& Dusek, 1980; Orlofsky \& O'Heron; 1987; Marsh \& Byrne 1991).

Entretanto, por ser o autoconceito uma estrutura fortemente influenciada pela cultura e devido às diferenças educacionais impostas pelos meios sócio-culturais para homens e mulheres, pode-se esperar que os esquemas masculino e feminino difiram em função do sexo. Há poucos estudos em literatura que descrevem diferenças no autoconceito de homens e mulheres (Franzoi \& Shields, 1984; Josephs, Markus \& Tafarodi, 1992; Marsh, 1989; Marsh, Craven \& Debus, 1991) e apenas um descrevendo diferenças na composição dos esquemas de gênero em função do sexo (Giavoni \& Tamayo, 2003).

Baseado, portanto, no estudo de Giavoni e Tamayo (2003) acima mencionado, este estudo teve como objetivo construir e validar um instrumento psicométrico que permitisse avaliar a composição dos esquemas de gênero que compõem o autoconceito dos homens.

\section{Método}

A metodologia utilizada para a construção e validação do Inventário Masculino dos Esquemas de Gênero do Autoconceito (IMEGA) baseou-se nas estruturas fatoriais encontradas para as escalas masculina e feminina do Inventário dos Esquemas de Gênero do Autoconceito (IEGA) (Giavoni \& Tamayo, 2000). Devidamente validado, o IEGA permite avaliar como os construtos sociais de masculinidade e feminilidade encontram-se estruturados na subjetividade individual. Os fatores das escalas masculina e feminina do IEGA representam os diferentes aspectos que formam os esquemas masculino e feminino presentes no autoconceito.

Para tanto, as escalas masculina e feminina que compõem este inventário foram analisadas separadamente, levando-se em consideração o sexo dos sujeitos (Giavoni, no prelo). A amostra masculina utilizada para estas análises foi composta por 592 estudantes universitários, solteiros $(89,4 \%)$, com faixa etária média de 22,23 anos $(D P=4,77$ anos).

Utilizando-se a estrutura original do IEGA, composta por 117 itens subdivididos em duas escalas - escala mascu- 
lina com 54 itens e a escala feminina com 63 itens - foram realizadas Análises dos Componentes Principais e Análises Fatoriais para cada uma das escalas, separadamente. Para as escalas masculina e feminina, respectivamente, a Análise dos Componentes Principais apresentou os seguintes resultados: 1) Escala masculina: a) Kaiser-Meyer-Olkin $(K M O)=0,86$; b) Bartlett's Test of Sphericity $(1378)=8456,787 ; p<0,001$; c) número de componentes (eigenvalue $>1,5)=6 \mathrm{e}$ d) variância total explicada pelos seis componentes: $38,93 \%$ e 2) Escala Feminina: a) Kaiser-Meyer-Olkin $(K M O)=0,89$; b) Bartlett's Test of Sphericity $(1953)=12221,876 ; p<0,001 ; \mathrm{c})$ número de componentes (eigenvalue $>1,5)=7$ e d) variância total explicada pelos sete componentes: $42,64 \%$.

O gráfico scree plot da escala masculina sinalizou a existência de quatro fatores e o gráfico da escala feminina sinalizou a existência de cinco fatores. Através do método Principal Axis Factoring (PAF), com rotações oblíquas e cargas fatoriais iguais ou superiores a 0,35 , foram extraídos quatro fatores principais para a escala masculina, denominados de: Negligência, Racionalidade, Ousadia e Agressividade e um fator de segunda ordem - Antipatia. Para a escala feminina foram extraídos cinco fatores principais, denominados de: Emotividade, Insegurança, Sensualidade, Responsabilidade e Tolerância e um fator de segunda ordem - Sensibilidade.

Os resultados obtidos na análise da consistência interna dos fatores, nos quais alguns fatores apresentaram índices de consistência interna abaixo dos padrões psicométricos, somados ao fato do IEGA ser composto por adjetivos que aumentam a variabilidade das respostas, levaram à elaboração do Inventário Masculino dos Esquemas de Gênero do Autoconceito (IMEGA).

O primeiro procedimento adotado para a construção do IMEGA foi a inclusão de itens (adjetivos), principalmente nos fatores das escalas masculina e feminina do IEGA que apresentaram baixos índices de consistência interna. Foram incluídos itens nos seguintes fatores: Negligência (preguiçoso, negligente e descuidado); Agressividade (rude, severo, maldoso, injusto, depreciador, genioso, ingrato e insensível); Racionalidade (direto, prático, determinado, crítico, franco, lógico, frio e pensador) e Ousadia (corajoso, audacioso, atrevido, independente, guerreiro, explorador, líder e herói) da escala masculina e nos fatores Sensualidade (sedutor, charmoso e bonito); Responsabilidade (honesto, grato e leal) e Tolerância (piedoso, altruísta, bondoso, indulgente, religioso, caridoso e grato) da escala feminina.

Após a inclusão dos itens nos fatores foram elaboradas frases para cada item. Estas frases visavam diminuir a variância apresentada pelos itens, enquanto adjetivos. Avaliando-se o conteúdo de cada fator, procurou-se, através das frases, abarcar os diversos aspectos que o compunham. Assim, por exemplo, as frases construídas para o fator Agressividade procuraram abordar os diferentes aspectos que formam este fator, tais como: antipatia, intransigência, violência, irritabilidade, grosseria e incompreensão. Neste sentido, foi elaborada uma série de frases para cada item. As frases elaboradas para o item Irritado do fator Agressividade encontram-se apresentadas abaixo.

Item Irritado: a) Irrito-me quando os outros não compartilham de meus pontos-de-vista; b) Irrito-me quando os outros discordam de meus pontos-de-vista; c) Fico irritado ao não ser compreendido pelas pessoas e d) Fico irritado quando as pessoas não compreendem os meus pontos-de-vista.

Procedimento semelhante foi realizado para todos os itens que compõem os demais fatores do IEGA. A seleção das frases que melhor descreviam cada item foi efetuada através de um grupo de pesquisa, composta por estudantes universitários (graduação e pós-graduação), de ambos os sexos, do Instituto de Psicologia da Universidade de Brasília.

Para esta etapa de seleção das frases foi entregue a cada sujeito do grupo de pesquisa, um questionário contendo o nome de cada fator, os itens que o compõem e as frases elaboradas para cada item. Foram realizadas duas reuniões para esta etapa de seleção das frases. Nestas reuniões foram analisados os fatores da escala masculina e os fatores da escala feminina do IEGA, respectivamente.

Os procedimentos utilizados nestas reuniões, para a avaliação dos fatores, foram: a) entrega do questionário aos sujeitos; b) apresentação dos fatores e seus respectivos itens; c) apresentação das frases elaboradas para descrever cada item; d) focalização sobre um único fator, os itens que o compõem e suas respectivas frases; e) intervalo de tempo para que cada sujeito escolhesse a melhor frase que descrevesse cada item do fator; f) anotação do percentual de concordância para cada frase escolhida; g) anotação de sugestões para melhorar o sentido semântico de cada frase e h) anotação de novas frases propostas.

Após esta etapa de seleção de frases foi elaborado um protótipo do IMEGA. As frases selecionadas na etapa anterior foram dispostas aleatoriamente ao longo do instrumento. Este protótipo, destinado a avaliar o autoconceito, solicitava ao respondente que avaliasse o quanto cada frase se aplicava a ele. Para tanto, o respondente deveria utilizar uma escala de cinco pontos ( 0 a 4 ), na qual o escore 0 (zero) indicava que a frase "não se aplicava" ao respondente até o escore 4, indicando que a frase "aplicava-se totalmente" ao respondente.

Este protótipo do IMEGA foi aplicado a uma amostra de cinco estudantes do sexo masculino (graduação), do Instituto de Psicologia da Universidade de Brasília. A aplicação deste protótipo à amostra ocorreu em uma sala de aula da instituição. Pouquíssimas alterações foram realizadas no instrumento após a análise semântica. Foram detectados alguns erros de digitação e detecção de oito frases com sentido amplo.

Após a análise semântica, o IMEGA passou a ser composto por 117 itens, subdivididos em duas escalas - escala masculina (65 itens) e escala feminina (52 itens). Para a validação do IMEGA, este foi aplicado a uma amostra cujo único critério exigido dos respondentes estava em possuir nível de escolaridade igual ou superior ao segundo grau completo. A amostra do IMEGA foi composta por 598 homens, universitários $(85,6 \%)$, solteiros $(94,3 \%)$, com faixa etária média de 21,15 anos ( $D P=3,49$ anos).

$\mathrm{O}$ instrumento foi aplicado em duas etapas distintas. Em uma primeira etapa, utilizou-se a sala de exposições da biblioteca universitária. Para manter uma certa aleatoriedade da amostra, a cada três sujeitos que entravam na biblioteca, o terceiro era convidado a responder o questionário. Aceitando o convite, o sujeito era acompanhado até a sala de exposições por uma monitora, a qual entregavalhe o questionário e encaminhava-o para uma das mesas disponíveis no local. Após estes procedimentos, o sujeito 
iniciava o preenchimento do questionário e ao finalizá-lo, depositava-o em uma caixa designada à devolução. Na segunda etapa, os instrumentos foram aplicados em salas de aula. Participaram desta etapa nove turmas de disciplinas oferecidas pelos respectivos institutos e faculdades: Instituto de Psicologia $(N=4)$, Faculdade de Educação Física $(N=3)$ e Instituto de Tecnologia $(N=2)$.

\section{Resultados}

Uma análise preliminar foi realizada sobre os dados obtidos na amostra masculina. Dos questionários aplicados, cinco foram retirados da amostra por apresentarem padrão de repetição nas respostas e/ou por estarem incompletos. Em todas as variáveis, os casos faltosos (missing values) foram inferiores a 5\%. Estes casos faltosos foram substituídos pelas médias obtidas para cada variável. O estudo da normalidade apresentou doze variáveis com elevada assimetria e curtose, dentre estas, sete eram da escala masculina e cinco da escala feminina. Foram realizadas transformações do tipo raiz quadrada sobre estas variáveis.

Um dos critérios para a análise da linearidade é a avaliação de pares de variáveis, através dos gráficos de dispersão. De acordo com Tabachnick e Fidell (1996), a combinação par-a-par de todas as 117 variáveis presentes no instrumento, resultaria em um número elevado de combinações, tornando impraticável este método de avaliação. Optou-se, portanto, em analisar, apenas, a linearidade daquelas variáveis que apresentassem desvios de normalidade. Para tanto, utilizou-se como critério de avaliação que cada par de variáveis fosse constituído por uma variável com bons índices de normalidade e outra variável com elevada assimetria e curtose. Foram analisados 30 pares de variáveis.

Para avaliar os casos de outliers multivariados optou-se por analisar, separadamente, as escalas masculina e feminina que compõem o instrumento. Isto porque, estas duas escalas serão analisadas e utilizadas individualmente. Assim, os casos de outliers multivariados que possam existir frente aos itens de uma das escalas, podem não ser os mesmos casos frente aos itens da outra escala.

Utilizando a distância Mahalanobis como critério de avaliação dos casos de outliers multivariados, foram encontrados para a escala masculina $\left(\chi^{2}(65)=105.962 ; \alpha=0,001\right) \mathrm{em}$ um total de 41 casos. Optou-se por retirar estes casos, restando 557 sujeitos na composição final da amostra masculina.

Para a escala feminina $\left(\chi^{2}(55)=93.134 ; \alpha=0,001\right)$ foram encontrados 26 casos de outliers multivariados. Estes casos foram retirados da amostra, restando um total de 572 sujeitos. Somente nove, dos 67 casos de outliers multivariados encontrados nas escalas masculina e feminina coincidiram ser outliers multivariados em ambas as escalas.

Em uma avaliação preliminar foram realizadas duas Análises dos Componentes Principais e duas Análises Fatoriais para cada escala. Na primeira análise, utilizou-se variáveis sem transformação e, na segunda análise, as variáveis com baixos índices de normalidade foram substituídas por suas versões transformadas. Não foram encontradas diferenças nas estruturas fatoriais e na variância total ao se utilizar as variáveis transformadas. Optou-se, portanto, pela utilização destas variáveis sem suas respectivas transformações. a) Escala Masculina:

A Análise dos Componentes Principais apresentou os seguintes resultados para a escala masculina: a) KaiserMeyer-Olkin $(K M O)=0,88$; b) Bartlett's Test of Sphericity $(2080)=11979,11 ; p<0,001 ; c)$ número de componentes (eigenvalue $>1,5)=7$ e d) variância total explicada pelos sete componentes: $40,95 \%$.

O gráfico scree plot foi utilizado como sinalizador na opção do número de fatores a serem extraídos. Para a escala masculina, este gráfico definiu a extração de três fatores, os quais explicavam $28,75 \%$ da variância total.

Através do método Principal Axis Factoring (PAF), com rotação oblíqua do tipo Oblimin e cargas fatoriais iguais ou superiores a 0,35 , foram extraídos três fatores para a escala masculina. Observou-se, entretanto, que alguns itens possuíam baixa comunalidade com os demais itens, apresentando cargas fatoriais inferiores a 0,35. Optou-se pela retirada destes 17 itens, permanecendo 48 na composição final da escala.

Após a exclusão destes itens, uma nova Análise dos Componentes Principais foi realizada para a escala masculina. Para esta nova análise, encontraram-se os seguintes resultados: Kaiser-Meyer-Olkin $(K M O)=0,90$; b) Bartlett's Test of Sphericity $(946)=8564,535 ; p<0,001 \mathrm{ec}$ ) variância total explicada pelos três componentes: $36,44 \%$.

Através do método Principal Axis Factoring (PAF), com rotação oblíqua do tipo Oblimin e cargas fatoriais iguais ou superiores a 0,35 , foram extraídos três fatores para a escala masculina. Considerando correlações entre os fatores iguais ou superiores a 0,32 (Tabachnick \& Fidell, 1996), como ideais, observou-se na Matriz de Correlações entre os Fatores que estes três fatores não apresentavam correlações entre si.

Devido à ortogonalidade apresentada pelos três fatores, optou-se por uma nova extração fatorial, utilizando-se a rotação do tipo varimax. Assim, através do método Principal Axis Factoring (PAF), com rotação varimax e cargas fatoriais iguais ou superiores a 0,35 , foram extraídos três fatores para a escala masculina. A tabela 1 apresenta os três fatores extraídos para a escala masculina. Nesta tabela, foram inseridos os itens que compõem cada fator e suas respectivas cargas fatoriais. Os termos utilizados para designar cada fator seguiram um dos seguintes critérios: a) denominar o fator de acordo com um dos itens que apresentam maior carga fatorial ou b) denominá-lo segundo a sua característica geral.

Os fatores extraídos para a escala masculina foram denominados de: Egocentrismo (Fator 1); Ousadia (Fator 2) e Racionalidade (Fator 3). Estes fatores explicavam, respectivamente, $17,15 \% ; 14,19 \%$ e $5,10 \%$ da variância total e apresentaram os seguintes índices de consistência interna: Egocentrismo $(\alpha=0,89)$; Ousadia $(\alpha=0,83)$ e Racionalidade $(\alpha=0,78)$.

b) Escala Feminina:

A análise dos Componentes Principais apresentou os seguintes resultados para a escala feminina: a) KaiserMeyer-Olkin $(\mathrm{KMO})=0,85 ; \mathrm{b})$ Bartlett's Test of Sphericity $(1326)=9870,059 ; p<0,001 ; c)$ número de componentes (eigenvalue $>1,5)=7$ e d) variância total explicada pelos sete componentes: $44,26 \%$.

Utilizando o gráfico scree plot como sinalizador na opção do número de fatores a serem extraídos, foram extraídos 
Tabela 1. Itens e cargas fatoriais dos fatores da escala masculina

\begin{tabular}{|c|c|c|}
\hline & Itens & C. F. \\
\hline \multicolumn{3}{|c|}{ Fator 1 - Egocentrismo } \\
\hline 1) & Sou injusto com as pessoas quando tenho os meus desejos contrariados & 0,69 \\
\hline 2) & Sou grosseiro com aqueles que discordam de minhas opiniões & 0,69 \\
\hline 3) & Quero que minhas opiniões prevaleçam sobre as dos demais & 0,66 \\
\hline 4) & Gosto de exercer o controle sobre os outros & 0,60 \\
\hline 5) & Faço comentários depreciativos daquilo e/ou daqueles que me incomodam & 0,60 \\
\hline 6) & Fico mal-humorado quando contrariam os meus desejos & 0,58 \\
\hline 7) & Trato rudemente as pessoas & 0,57 \\
\hline 8) & Agrido as pessoas, fisicamente e/ou verbalmente, quando me sinto frustrado & 0,56 \\
\hline 9) & Fico violento ao ser contrariado & 0,56 \\
\hline 10) & Sinto prazer em cutucar os pontos fracos das pessoas & 0,53 \\
\hline 11) & Fico irritado quando as pessoas não compreendem os meus pontos-de-vista & 0,52 \\
\hline 12) & Minhas atitudes impulsivas acabam atingindo terceiros & 0,50 \\
\hline 13) & Gosto de dar a última palavra & 0,49 \\
\hline 14) & Quero que os meus desejos prevaleçam sobre os dos demais & 0,49 \\
\hline 15) & Torno-me desagradável quando sou obrigado a fazer aquilo que não quero & 0,49 \\
\hline 16) & Aponto os erros cometidos pelos outros & 0,48 \\
\hline 17) & Digo coisas insensatas ao sentir-me pressionado emocionalmente & 0,47 \\
\hline 18) & Transfiro para os outros aquelas tarefas que deixei de cumprir & 0,44 \\
\hline 19) & Critico as pessoas quando estas cometem erros & 0,43 \\
\hline 20) & Por preguiça, deixo para amanhã o que posso fazer hoje & 0,41 \\
\hline 21) & Sou negligente com coisas importantes & 0,40 \\
\hline 22) & Sou ingrato com aqueles que me ajudam & 0,38 \\
\hline 23) & Sou inflexível quanto aos meus pontos-de-vista e opiniões & 0,37 \\
\hline 24) & Sou indiferente ao sofrimento dos outros & 0,36 \\
\hline \multicolumn{3}{|c|}{ Fator 2 - Ousadia } \\
\hline 1) & Gosto de enfrentar novos desafios & 0,69 \\
\hline 2) & Busco minhas metas com determinação & 0,68 \\
\hline 3) & Luto pelos meus ideais & 0,67 \\
\hline 4) & Luto por aquilo que desejo & 0,66 \\
\hline 5) & Vivo a procura de novos desafios & 0,62 \\
\hline 6) & Procuro ser o melhor naquilo que faço & 0,57 \\
\hline 7) & Gosto de desbravar ambientes desconhecidos & 0,47 \\
\hline 8) & Gosto de assumir a liderança nas atividades & 0,44 \\
\hline 9) & Busco prazer em tudo o que faço & 0,42 \\
\hline 10) & Mal terminei uma atividade e já estou pensando na próxima & 0,40 \\
\hline & Sou crítico & 0,36 \\
\hline \multicolumn{3}{|c|}{ Fator 3 - Racionalidade } \\
\hline 1) & Exponho os meus pensamentos de forma lógica & 0,62 \\
\hline 2) & Sou realista & 0,58 \\
\hline 3) & Sou do tipo racional & 0,56 \\
\hline 4) & Trato os assuntos com objetividade & 0,54 \\
\hline 5) & Encaro os fatos com objetividade, sem me emocionar & 0,53 \\
\hline & Resolvo os problemas de forma prática & 0,51 \\
\hline
\end{tabular}

C.F. = Cargas Fatoriais

quatro fatores para a escala feminina, os quais explicavam $34,54 \%$ da variância total. Através do método Principal Axis Factoring (PAF), com rotação oblíqua do tipo Oblimin e cargas fatoriais iguais ou superiores a 0,35 , foram extraídos quatro fatores para a escala feminina. Observou-se, entretanto, que alguns itens possuíam baixa comunalidade com os demais itens, apresentando cargas fatoriais inferiores a 0,35. Optou-se pela retirada destes 17 itens, permanecendo 35 na composição final da escala.
Após a exclusão destes itens, uma nova Análise dos Componentes Principais foi realizada para a escala feminina. Foram encontrados os seguintes resultados: a) Kaiser-MeyerOlkin $(K M O)=0,86$; b) Bartlett's Test of Sphericity (435) $=6.437,962, p<0,001 \mathrm{e}$ c) variância total explicada pelos quatro componentes: $48,84 \%$.

Através do método Principal Axis Factoring (PAF), com rotação oblíqua do tipo Oblimin e cargas fatoriais iguais ou superiores a 0,35 , foram extraídos quatro fatores para a escala 
Tabela 2. Itens e cargas fatoriais dos fatores da escala feminina

\begin{tabular}{|c|c|c|}
\hline & Itens & C. F. \\
\hline \multicolumn{3}{|c|}{ Fator 1 - Integridade } \\
\hline 1) & Tomo cuidado para que minhas atitudes não venham prejudicar terceiros & 0,60 \\
\hline 2) & Sou honesto & 0,59 \\
\hline 3) & Sou grato àqueles que me ajudam & 0,57 \\
\hline 4) & Sou íntegro & 0,55 \\
\hline 5) & A lealdade faz parte dos princípios que regem a minha vida & 0,54 \\
\hline 6) & Tomo minhas decisões visando o bem, tanto para mim quanto para os demais & 0,50 \\
\hline 7) & A moral rege a minha conduta diária & 0,46 \\
\hline 8) & Respeito os espaços e limites dos outros & 0,43 \\
\hline 9) & Cumpro as minhas tarefas diárias para que estas não recaiam sobre os outros & 0,41 \\
\hline 10) & Procuro manter uma conversa agradável ao estar com outras pessoas & 0,41 \\
\hline 11) & Conforto as pessoas que dividem comigo os seus problemas & 0,39 \\
\hline \multicolumn{3}{|c|}{ Fator 2 - Sensualidade } \\
\hline 1) & Seduzo as pessoas com o meu charme e sensualidade & $-0,82$ \\
\hline 2) & Sou charmoso & $-0,81$ \\
\hline 3) & Minha conversa somada ao meu aspecto físico tornam-me atraente & $-0,75$ \\
\hline 4) & Sou sensual & $-0,70$ \\
\hline 5) & Minha beleza física atrai as pessoas & $-0,67$ \\
\hline 6) & Visto-me com elegância & $-0,53$ \\
\hline 7) & Preocupo-me com a minha aparência & $-0,51$ \\
\hline \multicolumn{3}{|c|}{ Fator 3 - Insegurança } \\
\hline 1) & Tenho medo de me expressar e ser criticado pelos demais & 0,70 \\
\hline 2) & Deixo de ousar porque tenho medo de errar e ser criticado pelos demais & 0,66 \\
\hline 3) & Vivo dividido entre aquilo que quero e aquilo que esperam de mim & 0,60 \\
\hline 4) & Dependo do apoio dos demais para me decidir & 0,55 \\
\hline 5) & Vivo de acordo com as expectativas dos outros & 0,54 \\
\hline 6) & Sou tímido & 0,46 \\
\hline 7) & Sinto-me deslocado em eventos sociais & 0,39 \\
\hline \multicolumn{3}{|c|}{ Fator 4 - Emotividade } \\
\hline 1) & Compartilho os meus sentimentos com a minha companheira & $-0,86$ \\
\hline 2) & Gosto de compartilhar os fatos diários vividos pela minha companheira & $-0,86$ \\
\hline 3) & Compartilho as alegrias e tristezas vividas pela minha companheira & $-0,82$ \\
\hline 4) & Compartilho as minhas emoções com a pessoa amada & $-0,78$ \\
\hline 5) & Estou presente quando a minha companheira necessita de algum apoio & $-0,64$ \\
\hline
\end{tabular}

C.F. $=$ Cargas Fatoriais

feminina. A tabela 2 apresenta os quatro fatores da escala feminina. Nesta tabela, foram inseridos os itens que compõem cada fator e suas respectivas cargas fatoriais.

Os quatro fatores extraídos para a escala feminina foram denominados de: Integridade (Fator1); Sensualidade (Fator 2); Insegurança (Fator3) e Emotividade (Fator 4). Estes fatores explicavam, respectivamente, 20,78\%; 11,44 $\% ; 8,79 \%$ e $7,83 \%$ da variância total e apresentaram os seguintes índices de consistência interna: Integridade $(\alpha=$ $0,79)$; Sensualidade $(\alpha=0,86)$; Insegurança $(\alpha=0,77)$ e Emotividade $(\alpha=0,90)$.

Considerando correlações entre os fatores iguais ou superiores a 0,32, como ideais, pôde-se observar na Matriz de Correlações entre os Fatores, que os fatores Integridade e Emotividade $(r=-0,34)$ estavam correlacionados, apresentando um fator de segunda ordem. Este fator de segunda ordem, denominado de Sensibilidade, explica 30,95\% da variância total e apresentou índice de consistência interna igual a $\alpha=0,85$. A tabela 3 apresenta o fator de segunda ordem - Sensibilidade, obtido para a escala feminina. Nesta tabela, foram inseridos os itens que constituem o fator, bem como, suas respectivas cargas fatoriais.

Os fatores extraídos para a escala masculina, representam aspectos da subjetividade social (masculinidade) que estão estruturados na subjetividade individual (autoconceito), compondo o esquema masculino. Estes fatores, enquanto componentes do esquema masculino, avaliam aspectos instrumentais do self. Poder-se-ia, portanto, considerar que os fatores da escala masculina representam os seguintes aspectos da masculinidade estruturados no self:

- Fator Egocentrismo: como característica geral, este fator focaliza o eu como centro de todo o interesse; um amor tão exclusivo a si que acaba por implicar na subordinação dos interesses dos outros ao seu próprio. Particularmente, avalia comportamentos relacionados à agressividade, autoritarismo, insensibilidade e negligência. Avalia a incapacidade do indivíduo de aceitar condições, opiniões e atitudes divergentes daquelas esperadas e desejadas por ele.

- Fator Ousadia: como característica geral, este fator fo- 
Tabela 3. Itens e cargas fatoriais do fator Sensibilidade da escala feminina

\begin{tabular}{|c|c|c|}
\hline & Itens & C. F. \\
\hline \multicolumn{3}{|c|}{ Fator - Sensibilidade } \\
\hline 1) & Compartilho as alegrias e tristezas vividas pela minha companheira & 0,72 \\
\hline 2) & Gosto de compartilhar os fatos diários vividos pela minha companheira & 0,70 \\
\hline 3) & Compartilho os meus sentimentos com a minha companheira & 0,67 \\
\hline 4) & Estou presente quando a minha companheira necessita de algum apoio & 0,65 \\
\hline 5) & Compartilho as minhas emoções com a pessoa amada & 0,61 \\
\hline 6) & Conforto as pessoas que dividem comigo os seus problemas & 0,50 \\
\hline 7) & Tomo cuidado para que minhas atitudes não venham a prejudicar terceiros & 0,48 \\
\hline 8) & Sou grato àqueles que me ajudam & 0,47 \\
\hline 9) & Sou honesto & 0,46 \\
\hline 10) & A lealdade faz parte dos princípios que regem a minha vida & 0,45 \\
\hline 11) & Tomo as minhas decisões visando o bem, tanto para mim quanto para os demais & 0,43 \\
\hline 12) & Sou íntegro & 0,43 \\
\hline 13) & Procuro manter uma conversa agradável ao estar com outras pessoas & 0,42 \\
\hline 14) & Cumpro as minhas tarefas para que estas não recaiam sobre os outros & 0,40 \\
\hline 15) & A moral rege a minha conduta diária & 0,39 \\
\hline
\end{tabular}

C. F. $=$ Cargas Fatoriais

caliza o grau de arrojamento do self, que busca no novo e no inusitado, a satisfação de seus objetivos, metas e o prazer individual. Particularmente, este fator avalia comportamentos relacionados à ousadia de submeterse a novos desafios, à coragem e determinação de lutar pelos desejos e ideais, a busca do prazer individual, da liderança, competitividade e espírito de aventura.

- Fator Racionalidade: A característica geral deste fator enfoca a razão, enquanto instrumento que permite ao self explorar e compreender o seu ambiente, conhecer e relacionar objetos e/ou idéias; medir e calcular, refletir, deduzir, considerar, discorrer e expressar-se. Particularmente, o fator avalia comportamentos derivados do uso da razão, tais como: objetividade, praticidade, racionalismo, realismo e lógica.

Os fatores extraídos para a escala feminina, representam aspectos da subjetividade social (feminilidade) que estão estruturados na subjetividade individual (autoconceito), compondo o esquema feminino. Estes fatores, enquanto componentes do esquema feminino, avaliam aspectos coletivistas do self. Poder-se-ia, portanto, considerar que os fatores da escala feminina representam os seguintes aspectos da feminilidade estruturados no self:

- Fator Integridade: como característica geral, este fator focaliza os princípios e valores que regem a conduta do self. Particularmente, avalia valores individuais condizentes com as normas sociais, tais como: moralidade, integridade, lealdade e honestidade; e valores coletivistas de preocupação e interesse pelo bem-estar alheio, tais como: respeito, gratidão e bondade.

- Fator Sensualidade: como característica geral, este fator focaliza a auto-imagem e sua influência na interação com os outros. Particularmente, avalia aspectos sensoriais do self, traduzidos na sensualidade, charme e sedução; aspectos somáticos do self, expressos na beleza física e sua atratividade e aspectos estéticos do self, representados pela vaidade e elegância.

- Fator Insegurança: como característica geral, este fator focaliza a insegurança e a dependência do self, em relação às opiniões e expectativas dos outros. Particularmente, avalia o medo à rejeição, a dependência e subordinação às opiniões dos outros, a timidez e a introversão.

- Fator Emotividade: como característica geral, este fator focaliza aspectos afetivos do self. Particularmente, avalia a livre expressão das emoções e dos sentimentos, assim como, o grau de compartilhamento e comprometimento afetivo do self.

- Fator Sensibilidade: este fator reúne, em si, os fatores Integridade e Emotividade, focalizando um aspecto subjacente a estes dois fatores. Este aspecto subjacente, elo dos dois fatores, é a sensibilidade do self que procura traduzir, em comportamentos, os seus princípios e valores pessoais. Ajustamento às normas sociais, preocupação com o bem-estar alheio, livre expressão das emoções e sentimentos, compartilhamento e comprometimento afetivos, são alguns dos aspectos avaliados por este fator.

Comparando os fatores obtidos para as escalas masculina e feminina do IMEGA, com os fatores obtidos para as escalas masculina e feminina do IEGA, obtém-se as seguintes analogias semânticas:

a) Escala Masculina:

- Fator Egocentrismo: reúne os fatores Agressividade e Indiferença do IEGA;

- Fator Ousadia: equivalência semântica ao fator $O u$ sadia do IEGA e

- Fator Racionalidade: equivalência semântica ao fator Racionalidade do IEGA.

Por ser erigido sobre a estrutura fatorial da escala masculina do IEGA, esperava-se extrair quatro fatores da escala masculina do IMEGA. Entretanto, o gráfico scree plot definiu a extração de três fatores. Dos três fatores extraídos para a escala masculina, observa-se que o fator - Egocentrismo reúne os fatores linearmente dependentes - Agressividade e Indiferença $(r=-0,36)$ do IEGA (Giavoni \& Tamayo, 2000).

b) Escala Feminina:

- Fator Integridade: reúne os fatores Responsabilidade e Tolerância do IEGA; 
- Fator Sensualidade: equivalência semântica ao fator Sensualidade do IEGA;

- Fator Insegurança: equivalência semântica ao fator Insegurança do IEGA;

- Fator Emotividade: equivalência semântica ao do fator Emotividade do IEGA;

- Fator Sensibilidade: reúne os fatores Tolerância, Responsabilidade e Emotividade do IEGA.

Por ser erigido sobre a estrutura fatorial da escala feminina do IEGA, tinha-se a expectativa de extrair cinco fatores da escala feminina do IMEGA. Entretanto, o gráfico scree plot definiu a extração de quatro fatores. Dos quatro fatores extraídos para a escala feminina, observa-se que o fator - Integridade reúne os fatores linearmente independentes - Responsabilidade e Tolerância, do IEGA. No estudo de Giavoni e Tamayo (2000), apesar dos fatores Responsabilidade $x$ Tolerância não atingirem o índice estipulado de correlação entre os fatores $(r=0,32)$, eles apresentam elevado índice de correlação $(r=-0,31)$. Provavelmente, esta tendência à correlação somada às características dos itens elaborados para compor estes fatores no IMEGA acabou por torná-los linearmente dependentes, o que resultou em um único fator - o fator Integridade.

No IMEGA, o fator Integridade apresenta-se correlacionado ao fator Emotividade, resultando em um fator de segunda ordem - o fator Sensibilidade. No IEGA, os fatores Emotividade $x$ Responsabilidade $(r=0,36)$, Emotividade $x$ Tolerância $(r=-0,30)$ e Responsabilidade $x$ Tolerância $(r=-0,31)$ apresentam altos índices de correlação, podendo resultar em um único fator de segunda ordem. Observa-se, portanto, que em ambos os instrumentos manteve-se o padrão de correlação entre os fatores.

Conclui-se, portanto, que os fatores extraídos para as escalas masculina e feminina do IMEGA correspondem às estruturas fatoriais da escalas masculina e feminina do IEGA. Devidamente validado, o IMEGA pode ser utilizado para avaliar os esquemas masculino e feminino, de indivíduos do sexo masculino. $\mathrm{O}$ instrumento e sua tabela de correção encontram-se nos anexos 1 e 2 , respectivamente.

\section{Conclusão}

A metodologia utilizada para a construção do IMEGA, bem como o tratamento estatístico aplicado às escalas masculina e feminina, garantem a validade de construto do mesmo (Pasquali, 1996). Sendo a validade de construto uma maneira direta de verificar a hipótese da legitimidade da representação comportamental dos traços latentes (Pasquali, 1996, p. 94), pode-se afirmar que o IMEGA avalia os esquemas masculino e feminino do autoconceito dos homens.

Os resultados obtidos para o IMEGA permitem retirar importantes conclusões que contribuem para a sua validação. Como descrito anteriormente, o autoconceito é concebido como sendo uma estrutura multifacetada e maleável composta por uma coletânea de auto-representações. Um sistema que associa, organiza e coordena a variedade de imagens, esquemas, teorias, conceitos, metas e ideais que possuímos de nós mesmos. Enquanto autoconstrução teórica, o autoconceito encontra-se diretamente influenciado e vinculado à cultura na qual encontra-se inserido. Dentre os aspectos sócio-culturais que influenciam a formação do autoconceito, encontram-se os construtos sociais de masculinidade e feminilidade.

Segundo adeptos da teoria do auto-esquema (Markus, 1977; Markus \& cols., 1982), alguns indivíduos utilizam características referentes aos conceitos de masculinidade e feminilidade em suas autodescrições. Para esta teoria, estas características são consideradas auto-esquemas que, dentre outros auto-esquemas, formam o autoconceito. Quando estimulados, os auto-esquemas relacionados ao gênero tendem a se agrupar formando os esquemas de gênero.

Alicerçado na teoria do auto-esquema e, portanto, compartilhando a noção de esquemas de gênero, este estudo demonstra ser o autoconceito formado por duas estruturas cognitivas (esquema masculino e esquema feminino) que definem aspectos relacionados ao gênero. Estas estruturas cognitivas representam como os construtos sociais de masculinidade e feminilidade encontram-se estruturados na subjetividade individual.

Os resultados obtidos para o IMEGA demonstram, ainda, que assim como os construtos sociais de masculinidade $\mathrm{e}$ feminilidade, os esquemas masculino e feminino que compõem o autoconceito dos homens são formados por estruturas multidimensionais. $\mathrm{O}$ esquema masculino constituído por características autodescritivas provenientes do conceito de masculinidade é composto por três fatores ortogonais (Egocentrismo, Ousadia e Racionalidade) e o esquema feminino é composto por quatro fatores principais (Integridade, Sensualidade, Insegurança e Emotividade) e um fator de segunda ordem - Sensibilidade.

Comparando as estruturas fatoriais obtidas para os esquemas masculino e feminino que compõem o autoconceito dos homens no IEGA, com as estruturas obtidas para ambos os esquemas no IMEGA, observa-se uma consistência estrutural semântica. Esta consistência estrutural que permeia os instrumentos contribui para a validade de construto dos mesmos, ou seja, pode-se afirmar que estes instrumentos avaliam os esquemas masculino e feminino que compõem o autoconceito dos homens.

Enquanto estruturas multidimensionais observam-se que os esquemas masculino e feminino são formados por dimensões com valências positivas e negativas, e que, assim como os construtos sociais de masculinidade e feminilidade caracterizam aspectos individualistas e coletivistas do self, respectivamente. Esta relação entre os esquemas de gênero e os aspectos individualistas - coletivistas do self recebe suporte dos estudos de Flaherty e Dusek (1980), Orlofsky e O'Heron (1987) e Marsh e Byrne (1991), que demonstram correlações positivas entre características que definem aspectos instrumentais do self com a masculinidade e características que definem aspectos expressivos do self com a feminilidade.

Cabe, entretanto, ressaltar que o instrumento foi aplicado a uma amostra homogênea constituída por estudantes universitários, sendo oportuna uma nova validação sobre amostras que difiram quanto à escolaridade, nível sócio-econômico e cultural. Além disso, o IMEGA permitirá avaliar a interação existente entre os esquemas masculino e feminino que compõem o autoconceito dos homens, ou seja, através do IMEGA pode-se avaliar as infinitas combinações dos esquemas masculino e feminino, quando estes forem analisados como um par. Estas são algumas propostas para estudos futuros. 


\section{Referências}

Baldwin, M.W. \& Holmes, J.G. (1987). Salient private audiences and awareness of the self. Journal of Personality and Social Psychology, 52(6), 1087-1098.

Banaji, M.R. \& Prentice, D.A. (1994). The self in social contexts. Annual Review of Psychology, 45, 297-332.

Berndt, T.J. \& Perry, T.B. (1986). Children's perceptions of friendships as supportive relationships. Developmental Psychology, 22(5), 640-648.

Bracken, B.A (1996). Handbook of self-concept: Developmental, social and clinical considerations. New York: John Wiley \& Sons, Inc.

Burke, P.A., Kraut, R.E. \& Dworkin, R.H. (1984). Traits, consistency, and self-schemata: what do our methods measure? Journal of Personality and Social Psychology, 47(3), 568-579.

Epstein, S. (1973). The self-concept revisited. American Psychologist, 28(5), 405-416.

Flaherty, J.F. \& Dusek, J.B. (1980). An investigation of the relationship between psychological androgyny and components of self-concept. Journal of Personality and Social Psychology, 38(6), 984-992.

Franzoi, S.L. \& Shields, S.A. (1984). The body esteem scale: multidimensional structure and sex differences in a college population. Journal of Personality Assessment, 48 (2), 173-178.

Furman, W. \& Buhrmester, D. (1985). Children's perceptions of the personal relationships in their social networks. Developmental Psychology, 21(6), 1016-1024.

Giavoni, A. \& Tamayo, A. (2003). Diferenças na composição dos esquemas de gênero de homens e mulheres. Psicologia: Teoria, Investigação e Prática, 8(3), 145-160.

Giavoni, A. \& Tamayo, A. (2000). Inventário dos Esquemas de Gênero do Autoconceito (IEGA). Psicologia: Teoria e Pesquisa, 16(2), 175-184.

Harter, S. (1996). Historical roots of contemporary issues involving self-concept. Em B.A. Bracken (1996). Handbook of self-concept: Developmental, social, and clinical considerations (pp. 1-37). New York: John Wiley \& Sons, Inc.

James, W. (1890). Principles of psychology. Chicago: Encyclopedia Britannica.

Josephs, R.A., Markus, H.R. \& Tafarodi, R.W. (1992). Gender and self-esteem. Journal of Personality and Social Psychology, 63(3), 391-402.

Kashima, Y., Kim, V., Gelfand, M.J., Yamaguchi, S., Choi, S.C. \& Yuki, M. (1995). Culture, gender, and self: a perspective from individualism-collectivism research. Journal of Personality and Social Psychology, 69(5), 925-937.

Markus, H. (1977). Self-information and processing information about the self. Journal of Personality and Social Psychology, 35(2), 63-78.

Markus, H., Crane, M., Bernstein, S. \& Siladi, M. (1982). Self-schemas and gender. Journal of Personality and Social Psychology, 42(1), 38-50.
Markus, H. \& Kitayama, S. (1991). Culture and the self: Implications for cognition, emotion, and motivation. Psychological Review, 98(2), 224-253.

Markus, H. \& Kunda, Z. (1986). Stability and malleability of the self-concept. Journal of Personality and Social Psychology, 51(4), 858-866.

Markus, H. \& Nurius, P. (1986). Possible selves. American Psychologist, 41(9), 954-969.

Markus, H. \& Wurf, E. (1987). The dynamic self-concept: a social psychological perspective. Annual Review of Psychology, 38, 299-337.

Marsh, H.W. (1989). Sex differences in the development of verbal and mathematics constructs: the high school and beyond study. American Educational Research Journal, 26(2), 191-225.

Marsh, H.W., Barnes, J. \& Richards, G.E. (1986). Multidimensional self-concepts: the effect of participation in an Outward Bound Program. Journal of Personality and Social Psychology, 50(1), 195-204.

Marsh, H.W. \& Byrne, B.M. (1991). Differentiated additive androgyny model: relations between masculinity, femininity, and multiple dimensions of self-concept. Journal of Personality and Social Psychology, 61(5), 811-828.

Marsh, H.W., Craven, R.G. \& Debus, R. (1991). Self-concepts of young children 5 to 8 years of age: measurement and multidimensional structure. Journal of Educational Psychology, 83(3), 377-392.

Orlofsky, J.L. \& O'Heron, C.A. (1987). Stereotypic and nonstereotypic sex role trait and behavior orientations: implications for personal adjustment. Journal of Personality and Social Psychology, 52(5), 1034-1042.

Pasquali, L. (1996) (Org.). Teoria e métodos de medida em ciências do comportamento. Brasília: Laboratório de Pesquisa em Avaliação e Medida.

Rushton, J.P., Jackson, D.N. \& Paunonen, S.V. (1981). Personality: nomothetic or idiographic? A response to Kenrick and Stringfield. Psychological Review, 88(6), 582-589.

Sampson, E.E. (1985). The decentralization of identity: toward a revised concept of personal and social order. American Psychologist, 40(11), 1203-1211.

Showers, C.J., Abramson, L.Y. \& Hogan, M.E. (1998). The dynamic self: how the content and structure of the self-concept change with mood. Journal of Personality and Social Psychology, 75(2), 478-493.

Tabachnick, B.G. \& Fidell, L.S. (1996). Using multivariate statistics. California State University: HaperCollins College Publishers.

Triandis, H.C. (1989). The self and social behavior in differing cultural contexts. Psychological Review, 96(3), 506-520. 


\section{Anexo 1 - Inventário Masculino dos Esquemas de Gênero do Autoconceito (IMEGA)}

Neste questionário estão listadas algumas frases relacionadas ao autoconceito.

$\mathrm{O}$ autoconceito pode ser definido como a percepção que você possui de si mesmo.

Por favor, leia as frases abaixo e utilize a escala de 0 a 4 para avaliá-las.

A escala avalia o quanto cada frase se aplica a você.

$0=$ Não se aplica

$1=$ Aplica-se pouco

$2=$ Aplica-se moderadamente

$3=$ Aplica-se muito

4 = Aplica-se totalmente

Não é necessário que você se identifique e não há respostas certas ou erradas.

Evite deixar respostas em branco.

\begin{tabular}{|c|c|c|c|c|c|c|}
\hline & Itens & \multicolumn{5}{|c|}{ Escala } \\
\hline 01 & Respeito os espaços e limites dos outros & 0 & 1 & 2 & 3 & 4 \\
\hline 02 & Quero que os meus desejos prevaleçam sobre os dos demais & 0 & 1 & 2 & 3 & 4 \\
\hline 03 & Minha beleza física atrai as pessoas & 0 & 1 & 2 & 3 & 4 \\
\hline 04 & Transfiro para os outros aquelas tarefas que deixei de cumprir & 0 & 1 & 2 & 3 & 4 \\
\hline 05 & Critico as pessoas quando estas cometem erros & 0 & 1 & 2 & 3 & 4 \\
\hline 06 & Gosto de desbravar ambientes desconhecidos & 0 & 1 & 2 & 3 & 4 \\
\hline 07 & Fico violento ao ser contrariado & 0 & 1 & 2 & 3 & 4 \\
\hline 08 & Luto por aquilo que desejo & 0 & 1 & 2 & 3 & 4 \\
\hline 09 & Dependo do apoio dos demais para me decidir & 0 & 1 & 2 & 3 & 4 \\
\hline 10 & Sou sensual & 0 & 1 & 2 & 3 & 4 \\
\hline 11 & Encaro os fatos com objetividade, sem me emocionar & 0 & 1 & 2 & 3 & 4 \\
\hline 12 & Sou indiferente ao sofrimento dos outros & 0 & 1 & 2 & 3 & 4 \\
\hline 13 & Compartilho as minhas emoções com a pessoa amada & 0 & 1 & 2 & 3 & 4 \\
\hline 14 & Busco prazer em tudo o que faço & 0 & 1 & 2 & 3 & 4 \\
\hline 15 & Gosto de exercer o controle sobre os outros & 0 & 1 & 2 & 3 & 4 \\
\hline 16 & Visto-me com elegância & 0 & 1 & 2 & 3 & 4 \\
\hline 17 & Busco minhas metas com determinação & 0 & 1 & 2 & 3 & 4 \\
\hline 18 & Cumpro as minhas tarefas diárias para que estas não recaiam sobre os outros & 0 & 1 & 2 & 3 & 4 \\
\hline 19 & Trato os assuntos com objetividade & 0 & 1 & 2 & 3 & 4 \\
\hline 20 & Seduzo as pessoas com meu charme e sensualidade & 0 & 1 & 2 & 3 & 4 \\
\hline 21 & Sinto-me deslocado em eventos sociais & 0 & 1 & 2 & 3 & 4 \\
\hline 22 & Tomo minhas decisões visando o bem, tanto para mim quanto para os demais & 0 & 1 & 2 & 3 & 4 \\
\hline 23 & Agrido as pessoas, fisicamente e/ou verbalmente, quando me sinto frustrado & 0 & 1 & 2 & 3 & 4 \\
\hline 24 & Estou presente quando minha companheira necessita de algum apoio & 0 & 1 & 2 & 3 & 4 \\
\hline 25 & Luto pelos meus ideais & 0 & 1 & 2 & 3 & 4 \\
\hline 26 & Sou ingrato com aqueles que me ajudam & 0 & 1 & 2 & 3 & 4 \\
\hline 27 & Sinto prazer em cutucar os pontos fracos das pessoas & 0 & 1 & 2 & 3 & 4 \\
\hline 28 & Procuro ser o melhor naquilo que faço & 0 & 1 & 2 & 3 & 4 \\
\hline 29 & Fico mal-humorado quando contrariam os meus desejos & 0 & 1 & 2 & 3 & 4 \\
\hline 30 & Sou tímido & 0 & 1 & 2 & 3 & 4 \\
\hline 31 & Compartilho os meus sentimentos com a minha companheira & 0 & 1 & 2 & 3 & 4 \\
\hline 32 & Preocupo-me com a minha aparência & 0 & 1 & 2 & 3 & 4 \\
\hline 33 & Vivo dividido entre aquilo que quero e aquilo que esperam de mim & 0 & 1 & 2 & 3 & 4 \\
\hline 34 & Por preguiça, deixo para amanhã o que posso fazer hoje & 0 & 1 & 2 & 3 & 4 \\
\hline 35 & Aponto os erros cometidos pelos outros & 0 & 1 & 2 & 3 & 4 \\
\hline 36 & Gosto de assumir a liderança nas atividades & 0 & 1 & 2 & 3 & 4 \\
\hline 37 & Procuro manter uma conversa agradável ao estar com outras pessoas & 0 & 1 & 2 & 3 & 4 \\
\hline 38 & Tomo cuidado para que minhas atitudes não venham a prejudicar terceiros & 0 & 1 & 2 & 3 & 4 \\
\hline 39 & Sou do tipo racional & 0 & 1 & 2 & 3 & 4 \\
\hline 40 & Digo coisas insensatas ao sentir-me pressionado emocionalmente & 0 & 1 & 2 & 3 & 4 \\
\hline
\end{tabular}




\begin{tabular}{|c|c|c|c|c|c|c|}
\hline \multirow[b]{2}{*}{41} & \multirow{2}{*}{$\begin{array}{ll} & \text { Itens } \\
\text { Sou charmoso } & \end{array}$} & \multicolumn{5}{|c|}{ Escala } \\
\hline & & 0 & 1 & 2 & 3 & 4 \\
\hline 42 & Mal terminei uma atividade e já estou pensando na próxima & 0 & 1 & 2 & 3 & 4 \\
\hline 43 & Gosto de enfrentar novos desafios & 0 & 1 & 2 & 3 & 4 \\
\hline 44 & Compartilho as alegrias e tristezas vividas pela minha companheira & 0 & 1 & 2 & 3 & 4 \\
\hline 45 & Tenho medo de me expressar e ser criticado pelos demais & 0 & 1 & 2 & 3 & 4 \\
\hline 46 & Conforto as pessoas que dividem comigo os seus problemas & 0 & 1 & 2 & 3 & 4 \\
\hline 47 & Sou negligente com coisas importantes & 0 & 1 & 2 & 3 & 4 \\
\hline 48 & Quero que as minhas opiniões prevaleçam sobre as dos demais & 0 & 1 & 2 & 3 & 4 \\
\hline 49 & Minha conversa somada ao meu aspecto físico tornam-me atraente & 0 & 1 & 2 & 3 & 4 \\
\hline 50 & Sou grato àqueles que me ajudam & 0 & 1 & 2 & 3 & 4 \\
\hline 51 & Fico irritado quando as pessoas não compreendem os meus pontos-de-vista & 0 & 1 & 2 & 3 & 4 \\
\hline 52 & Gosto de compartilhar os fatos diários vividos pela minha companheira & 0 & 1 & 2 & 3 & 4 \\
\hline 53 & Sou grosseiro com aqueles que discordam de minhas opiniões & 0 & 1 & 2 & 3 & 4 \\
\hline 54 & Sou honesto & 0 & 1 & 2 & 3 & 4 \\
\hline 55 & Gosto de dar a última palavra & 0 & 1 & 2 & 3 & 4 \\
\hline 56 & Sou crítico & 0 & 1 & 2 & 3 & 4 \\
\hline 57 & Exponho os meus pensamentos de forma lógica & 0 & 1 & 2 & 3 & 4 \\
\hline 58 & A moral rege a minha conduta diária & 0 & 1 & 2 & 3 & 4 \\
\hline 59 & Sou realista & 0 & 1 & 2 & 3 & 4 \\
\hline 60 & Resolvo os problemas de forma prática & 0 & 1 & 2 & 3 & 4 \\
\hline 61 & A lealdade faz parte dos princípios que regem a minha vida & 0 & 1 & 2 & 3 & 4 \\
\hline 62 & Vivo de acordo com as expectativas dos outros & 0 & 1 & 2 & 3 & 4 \\
\hline 63 & Sou íntegro & 0 & 1 & 2 & 3 & 4 \\
\hline 64 & Faço comentários depreciativos daquilo e/ou daqueles que me incomodam & 0 & 1 & 2 & 3 & 4 \\
\hline 65 & Sou injusto com as pessoas quando tenho os meus desejos contrariados & 0 & 1 & 2 & 3 & 4 \\
\hline 66 & Trato rudemente as pessoas & 0 & 1 & 2 & 3 & 4 \\
\hline 67 & Deixo de ousar porque tenho medo de errar e ser criticado pelos demais & 0 & 1 & 2 & 3 & 4 \\
\hline 68 & Minhas atitudes impulsivas acabam atingindo terceiros & 0 & 1 & 2 & 3 & 4 \\
\hline 69 & Vivo a procura de novos desafios & 0 & 1 & 2 & 3 & 4 \\
\hline 70 & Torno-me desagradável quando sou obrigado a fazer aquilo que não quero & 0 & 1 & 2 & 3 & 4 \\
\hline 71 & Sou inflexível quanto aos meus pontos-de-vista e opiniões. & 0 & 1 & 2 & 3 & 4 \\
\hline
\end{tabular}

\section{Anexo 2 - Tabela de Correção do IMEGA}

O escore de cada fator será obtido através da média aritmética.

a) Escala Masculina:

Fator Egocentrismo: (v2, v4, v5, v7, v12, v15, v23, v26, v27, v29, v34, v35, v40, v47, v48, v51, v53, v55, v64, v65, v66, v68, v70 e v71). Fator Ousadia: (v6, v8, v14, v17, v25, v28, v36, v42, v43, v56 e v69).

Fator Racionalismo: (v11, v19, v39, v57, v59 e v60).

b) Escala Feminina:

Fator Integridade: (v1,v18,v22,v37,v38,v46,v50,v54,v58,v61 e v63).

Fator Sensualidade: (v3, v10, v16, v20, v32, v41 e v49).

Fator Insegurança: (v9, v21, v30, v33, v45, v62 e v67).

Fator Emotividade: (v13, v24, v31, v44 e v52).

Fator Sensibilidade: (v13, v18, v22, v24, v31, v37, v38, v44, v46, v50, v52, v54, v58, v61 e v63). 


\title{
INTERESSADO EM AGILIZAR A PUBLICAÇÃO DE SEU ARTIGO?
}

\section{Informações e dicas para os autores sobre aspectos operacionais}

\section{O manuscrito é reencaminhado pelo autor em versão reformulada}

\begin{abstract}
A produção gráfica do trabalho é executada através de editoração eletrônica, daí a exigência do exemplar em disquete, além de três exemplares em papel da versão reformulada. Quando a versão reformulada é aceita e são poucos os reparos, as correções necessárias são feitas na secretaria da revista. Com o disquete disponível o processamento pode ser imediatamente iniciado. Na falta de disquete não é possível o processamento de correções nem a preparação do manuscrito para editoração. Em suma, atraso para entrar no prelo.
\end{abstract}

\section{Informações e dicas para os autores com artigos no prelo}

\section{O manuscrito é encaminhado para editoração}

No caso de o manuscrito ser aceito para publicação, é esperada a participação do autor no processo de preparação do artigo na fase de editoração. A primeira prova do artigo, editada a partir da versão em disquete, é enviada para exame ao(s) autor(es). O prazo para devolução é de 48 horas. A obediência ao prazo permite a manutenção da composição prevista para o volume/ número da revista. $\mathrm{O}$ atraso no envio da prova examinada pode implicar em mudanças na composição de um número no prelo. E pode resultar em atraso na edição final. 